\title{
Grammatical Errors in Debate Arguments Made by Students of Global English Language Center
}

Adina Nikmawati, S. Pd., Prof. Dr. Indawan, M. Pd., Rini Susanti, S. Pd, M.A.

Universitas Muhammadiyah Palembang, Adina Nikmawati

Universitas Muhammadiyah Palembang, Indawan Syahri

Universitas Muhammadiyah Palembang, Rini Susanti

adina.nikmawati@gmail.com,rini_deddy@yahoo.com, indawansyahri_ump@yahoo.com

\begin{abstract}
The thesis entitled Grammatical Errors in Debate Arguments Made by the Students of Global English Language Center. The objectives of this study were (1) to find out the kinds of errors made by the students of Global English Language Center in their debate arguments and (2) to find out the causes of errors made by the students of Global English Language Center in their debate arguments. The writer used descriptive-qualitative method of research. The population of this study was all the students of Global English Language Center. The sample was chosen by using purposive sampling. The samples were 12 students which were grouped into two debate sessions. The data were calculated and analyzed based on surface strategy taxonomy and linguistic category taxonomy to know the errors. Samples' personal reasons and personal judgement were used to know the causes of the errors. The findings showed that there were four types of errors that the students made which are omission, addition, misformation, and misordering. Misformation is the major error made by the students. Nervousness, time limit, native language interference, and the insufficient grammar learning were the causes why the students made errors.
\end{abstract}

Indexing Terms/Keywords: Error Analysis, Debate Arguments, Kinds Of Error, And Causes Of Error

Academic Discipline And Sub-Disciplines: Education

Subject Classification: English

Type (Method/Approach): Descriptive Analaysis

Language: English

Date of Submission: 2018-04-09

Date of Acceptance: 2018-04-20

Date of Publication: 2018-04-30

ISSN: 2348-3024

Volume: 09 Issue: 01

Journal: Journal of Advances in Linguistics

Website: https://cirworld.com

This work is licensed under a Creative Commons Attribution 4.0 International License. 


\section{Introduction}

\section{Background of the study}

Grammar is one of English language aspects that must be learned and understood by the students because they cannot understand the sentences well without learning grammar. Downing and Locke (2006) state that, "grammar aims to match forms to function and meaning in context" (p.4). It is hoped by learning grammar students will be able to use the language precisely and accurately.

The students may commit error in debating because they think that the target language and their mother tongue are similar. In addition, they tend to translate their mother tongue to target language in inappropriate way. Broughton et al. (1980), "errors will always be made, and have direct implications for remedial work because they are by their nature systematic infringements of the normal." (p.9). In this case, errors will always happen and have aims for the next work or attempt. The aims prevent a learner to commit errors as well. So, to commit errors is normal because errors come casually. In keeping with the writer's experience when studying in Global English Language Center for six months, grammar is one of the language aspects which is complicated for the students. The writer still finds so many grammar errors when students are both speaking and debating. Finally, the writer is interested in conducting.

this study and discuss it under the title "Grammatical Errors in Debate Arguments Made by Students of Global English Language Center."

\section{Problem of the Study}

The problem of the study related to the inappropriate grammar used in argument of each speaker/debater in the debate itself which is continued to the next debates and the clarity of the argument because of the inappropriate grammar.

\section{Limitation of the Problem}

This study was limited to the kinds of error in debate arguments made by the students of Global English Language Center which is held weekly. There are many errors made by the students when stating their arguments in weekly debate. The writer limits the scope of the problem only on: grammatical errors in debate arguments.

\section{Objectives of the Study}

Based on the problems, the objectives of this study were:

1. To find out the kinds of errors made by the students of Global English Language Center in their debate arguments.

2. To find out the causes of errors made by the students of Global English Language Center in their debate arguments.

\section{Significance of the Study}

The results of the finding are expected to provide useful information about the common errors that made by the speakers in using grammar. The significance of this study is for:

\section{For the Writer}


The study enables the writer to recall the grammar learning and it can improve the comprehension of using grammar. Therefore, it adds set of experience of doing research.

\section{For the Teachers}

First, teachers know what kinds of error in using grammar in weekly debate. Second, by analyzing the common mistakes that made by the speakers or the students in that course, teachers could improve the quality of their teaching and the course itself.

\section{For the Students}

First, this study makes the students realize their grammar mistakes. Second, students can increase their knowledge about grammar especially about using grammar appropriately. Therefore, they can state their arguments in debate clearly.

\section{For the Other Writers}

This finding can be basic consideration to enrich the further writer's knowledge to conduct the further study.

\section{LITERATURE REVIEW}

\section{Error}

\section{Definition of Error}

Dulay et al. (1982) state that errors are the flawed side of learner speech or writing. They are those parts of conversation or composition that deviate from some selected norm of mature language performance. Studying learners' errors serve two major purposes (1) it provides data from which inferences about the nature of the language learning process can be made; and (2) it indicates to teachers and curriculum developers which part of the target language students have most difficulty producing correctly, and which error types detract most from a learner's ability to communicate effectively (p.138). In this case, learners infringe the rule of a language which resulting errors. Then, analyzing the errors shows two aims which are showing data and figuring out the difficulty in learning faced by students

In addition, Syahri and Susanti (2016) tell that commonly, the students and teachers of English come from the same cultural background with the same language too. It enables them to communicate and develop their ideas about the local culture they are familiar with than talk about the target culture which is new for them (p.2). This target culture problem is the same with target language which means there is no doubt that students tend to commit errors because it is new and not familiar to them.

\section{Errors versus Mistakes}

There are quite big differences between errors versus mistake. If we have not looked deep into this case, they seem similar, but they are not. Errors have more frequent occurrences while mistakes less.

Keshavarz (2012):

Errors are systematic, governed by rule, and appear because a learner's knowledge of the rules of the target language is incomplete. They are likely to occur repeatedly and not recognized by the learner. In contrast, mistakes are random deviations, unrelated to any system, and instead representing the same types of 
performance mistakes that might occur in the speech or writing of native speakers, such as slips of the tongue or pen, false starts, lack of subject-verb agreement in a long-complicated sentence, and the like (pp. 60-61).

It means the learner experiences errors for several times when he or she does not recognize them. The writer also can infer that errors occurs when the learner does not have sufficient information or knowledge about the rule of language learning. Whereas, mistake is the misuse of the rule of a language such as slip of the tongue, incompletion of parts of speech in a sentence and so on. Susanti (2016) states that feedback (corrections and comments) is needed to support students' writing development and build their confidence in writing (p.1063). In this case, so is feedback in speaking which speaking means delivering arguments to specify. The teacher or the debate trainer can give some feedback, so the students can speak confidently. Thus, it is also possible for the learner to correct their mistakes because they can recognize them.

\section{The Causes of Errors}

Touchie (1986) states that there are two major sources of error in learning second language. The first source is interference from the native language while the second source can be attributed to intralingual and developmental factors (p.77). One of the causes of why errors happen is the intervention of original language. The other one is intralingual and developmental factors.

Keshavarz (2012) states that intralingual and developmental errors are caused by the mutual interference of items in the target language, i.e., the influence of one target language item upon another. For instance, a learner may produce $\boldsymbol{H e}$ is comes, based on the blend of English structure: He is coming, and He comes (p.124). This means that errors also happen when there is a similarity in the target language itself.

In brief, errors are caused by two factors. They are the intervention of original or native language and the similarity in the target language.

\section{Typical Errors in English}

Dulay, Burt, and Krashen (1982) proposes surface strategy taxonomy which highlight the ways surface structures are altered (p.150).

\section{1) Omission}

Omission is the absence of an item that must appear in well-formed utterance. For instance:

a) He absent. (incorrect)

b) He is absent (correct)

The first sentence is incorrect because to be is does not appear. This shows that there is an omission.

\section{2) Addition}

Addition error is the opposite of omission which is presence of an item, which must not appear in a wellformed utterance. For example:

a) Andy go to school. (incorrect)

b) Andy goes to school. (correct)

The first sentence is incorrect because plural subject (Andy) must be followed by verb with additional s/es (goes). 


\section{3) Misformation}

It is the use of the Wrong form of morpheme or structure. For instance:

a) I buy a books. (incorrect)

b) I buy a book. (correct)

The first sentence is incorrect because the article " $a$ " is for singular noun

\section{4) Misordering}

Misordering or improper ordering is defined as the incorrect placement group of morpheme in an utterance. For example:

a) He comes see to her. (incorrect)

b) He comes to see her. (correct)

\section{Argument}

Sapir (2002; as cited in Syahri and Susanti, 2016), language is a purely human and non-instinctive method of communicating ideas, emotions, and desire by means of voluntarily produced symbols. It is used to express thoughts and to communicate information (p.2). Delivering argument is the form of expressing thoughts and communicating or giving information. Arguments contain of a lot of ideas about certain topics whether it is personal opinion or from any references. Debaters can highlight or emphasize the strong points of their arguments.

Besnard \& Hunter (2008) say:

An argument is a set of assumptions (i.e., information from which conclusions can be drawn), together with a conclusion that can be obtained by one or more reasoning steps (i.e., steps of deduction). The assumptions used are called the support (or, equivalently, the premises) of the argument, and its conclusion (singled out from many possible ones) is called the claim (or, equivalently, the consequent or the conclusion) of the argument. The support of an argument provides the reason (or, equivalently, justification) for the claim of the argument. (p.2).

Toulmin, Reike, and Janik (1984) in Wingate (2012) define argument similarly as 'the sequence of interlinked claims and reasons that, between them, establish content and force of the position for which a particular speaker is arguing' (p. 14). Furthermore, the term argument here refers to argument in a debate where several speakers are stating their thoughts about a motion. In addition, assumptions in argument can be from reliable references or resources which the accuracy are already proven or it can be from personal thoughts or opinions about something which in this case the way you see or the perception toward something.

\section{RESEARCH PROCEDURES}

\section{Method of Research}

In this study, the writer used descriptive-qualitative method. Glass \& Hopkins (1984) state that descriptive research involves gathering data that describes events then organizes, tabulates, depicts, and describes the data collection (in Knupfer \& McLelan, 1996, p.1197). The writer gathered the data when a debate was running and then transcribed. 
This research used qualitative method. Creswell (2014) states that "qualitative methods can be used to obtain the intricate details about phenomena such as feelings, thought processes, and emotions that are difficult to extract or learn about through more conventional methods" (p.45). According to Cohen, et al (2007) "qualitative data analysis involves organizing, accounting for and explaining the data; in short, making sense of data in terms of the participants' definitions of the situation, noting patterns, themes, categories and regularities" (p.461). In other words qualitative research focuses on describing, understanding and clarifying a human experience. Therefore the writer used descriptive qualitative study.

\section{Operational Definition}

To avoid misunderstanding what this study tells about the terms, the writer highlighted them as follow:

\section{Grammar}

The language aspect that was analyzed by the writer in debate arguments. In this case, grammar deals with the rule of good sentences with the appropriate structure of the language.

\section{Error Analysis}

The activity to observe and analyze the deviation of the students commit in debate then it will be analyzed and the deviation will be corrected. The writer also found the sources of the errors.

\section{Debate Argument}

A group of statements related to a motion spoken by debaters which contain facts, proof, and ideas. The writer could infer that students tend to commit error when they are stating their arguments in the debate.

\section{Population and Sample}

\section{Population}

Fraenkel et al (2012) say that "the group of interest to the researcher, the group to whom the researcher would like to generalize the results of the study (p.92). In general, population is a group of people who share the same characteristics and can be the object of a study. The population of this study was the students of Global English Language Center.

\section{Sample}

Purposive sampling is different from convenience sampling in that researchers do not simply study whoever is available but rather use their judgment to select a sample that they believe, based on prior information, will provide the data they need. (Fraenkel, et al., 2012, p.100). Therefore the technique used to take the sample is purposive sampling. The writer took the students who became debaters on Saturdays when the writer was conducting the research in Global English Language Center. In addition, the writer took two debate sessions so that the writer analyzed the arguments from twelve speakers.

\section{Technique for Collecting the Data}

In this study, the writer used documentation to collect the data. Syahri, et al (2017) state that documentation is the amount of facts and data stored in materials in the form of documentation and the main characteristic of the data store in a documentation is not limited through space and time (p.84). The writer can infer that the data that have been taken can be seen all the time and safely kept in a documentation. 
The writer used documentation which in this case the writer recorded the debate arguments delivered by the students from both teams that each team contains of three speakers. Those arguments were put in the form of table. The writer did a short interview to know the causes why the students commit grammatical errors. The interviews were recorded as well.

\section{Technique for Analyzing the Data}

The technique used was descriptive analytic method (coding). The writer described the errors made by the students of Global English Language Center. Those errors were put in some tables provided with the grammatical error and the correction. As guidance, the writer used the three books of Azar Grammar Series to give corrections.

These are some techniques that the writer used to analyze the data. The following techniques were:

1. Organizing the data

2. Analyzing the data

3. Putting the data collected in a table form

4. Coding or explaining the types of the errors and reconstructing them

5. Explaining the causes

\section{FINDINGS}

The Most Dominant Error

\begin{tabular}{|c|c|c|}
\hline No. & Types of Error & Percentage (\%) \\
\hline 1 & Omission & $42 \%$ \\
\hline 2 & Addition & $11 \%$ \\
\hline 3 & Misformation & $43 \%$ \\
\hline 4 & Misordering & $4 \%$ \\
\hline
\end{tabular}

From the finding above, the total frequency of all types of error is 184 errors. Omission was made 77 times which is $42 \%$ in all arguments while addition was made 21 times by the debaters so the percentage is $11 \%$. Therefore, they made misformation as the most dominant error because it has the highest percentage which is $43 \%$ and they made it 79 times. The lowest percentage belongs to misordering which is only $4 \%$ or 7 times. In this case, the students made misformation error more often rather than the other three types of error.

\section{Types of Errors}

\section{a. Omission}

Omission means the absence of an item that must appear in a well-constructed sentence. In this case, some words disappeared in arguments. For example: 
*(1) ... especially for football side that mix by personal politic. (minute 0)

*(2) FIFA make first rule and FIFA forbid government intervene...(minute 3)

*(3) Because if have basic in sport should be chairman in sport. If have basic in politic should be the politician.(minute 4)

*(4) because government involved in the affairs of sport. (minute 6)

*(5) okay let come to91 my case. (minute 7)

In the sentence * (1) if a passive voice is preceded by the determiner that, is should follow. The verb that follows must be in the form of past participle as well. So it becomes "especially for football side that is mixed by personal politic."

Next for sentence *(2) FIFA is a singular noun. Therefore the infinitive verb that follows should be with the singular marker or prefix s/es. The correct sentence is "FIFA makes first rule and FIFA forbids government intervene..."

Then, after the clause if, a subject should be inserted. Someone can be the singular subject and verb follows as well. As a result, the sentence should be "Because if someone has basic in sport should be chairman in sport. If someone has basic in politic should be the politician."

For sentence number *(4) a noun is usually modified by either a definite article or indefinite article. Since the noun government is specific, it should be preceded by article the. Then, it should be "because the government involved in the affairs of sport."

The last, after the word let, an object pronoun is attached. Therefore object pronoun me follows. It becomes "okay let me come to my case."

\section{b. Addition}

Addition means the presence or the existence of items that must not appear in a good sentence. The writer also found some addition errors as well. For instance:

*(1) in here we are agree about this motion this house... (minute 1)

*(2) ... Nurdin Khalid leaded in some period. (minute 7)

*(3) let me to rebut the second speaker of positive team. (minute 16)

*(4) ... actually ganeto was established after criticsm called POI and the main goal actually to show existences of Indonesia. (minute 18)

*(5) it's not genuine for make the soccer be better but there are many secret intention behind them. (minute 23)

In the sentence *(1) to be are is not needed because the verb agree is in the present form. It should be we agree instead.

Next, for sentence *(2) the root verb lead is an irregular verb, not a regular one. It must be led. As a result, it becomes ... Nurdin Khalid led in some period. 
Therefore, let is followed by the simple form of a verb, not an infinitive. Yet, it is let me rebutt the second speaker of positive team. The infinitive to is omitted.

While for number * (4) the noun existences is an uncountable noun. Therefore, the suffix $-s$ is not needed. In this case, the sentence ... actually ganeto was established after criticsm called POI and the main goal actually to show existence of Indonesia. suits best.

Then, the be in number *(5) is not needed because it should be in simple form which is it's not genuine for making the soccer better but there are many secret intention behind them.

\section{c. Misformation}

Misformation means the wrong use of structure or morpheme. The writer presented five examples out of many misformation errors.

*(1) I'm as positive team really agree about this motion this house believe that sport and politics should not mix. (Minute 15)

*(2) So ladies and gentlemen the connected between politics and sport is not new anymore. (Minute 16)

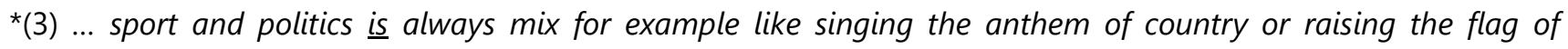
country. (Minute 21)

*(4) Because why? Before I come to my case, let me rebuttal first. (Minute 27)

*(5) I will talk about define the motion and a little bit about the advantages. (Minute 0)

In number *(1) the verb agree is always followed by the preposition with. Then, the preposition about should be replaced with the preposition with. So ladies and gentlemen I'm as positive team really agree with this motion this house believe that sport and politics should not mix suits best.

Next, there is a wrong word choice. Connected is an adjective yet, it should be in noun form. Connection suits best as well. It becomes so ladies and gentlemen the connection between politics and sport is not new anymore.

Moving on to number *(3) since the subjects are more than one, the plural verb should follow. Is is best replaced with are. It should be ... sport and politics are always mix for example like singing the anthem of country or raising the flag of country.

Then, let is followed by a verb, not a noun. Since rebuttal is a noun, it should be replaced with verb rebut. So, the sentence is best replaced with because why? Before I come to my case, let me rebut first.

The last, after preposition usually comes gerund as an object. The simple verb define should be changed to defining. The sentence should be I will talk about defining the motion and a little bit about the advantages.

\section{d. Misordering}

It is about incorrect placement of morpheme in an utterance. There are five examples that the writer found.

*(1) there are $50 \%$ of candidate the next chairman of Indonesia..." (minute 2)

*(2) what the suspect do in corruption? (minute 9) 
*(3) ...the discriminant of values genesis that form of punishment such as what are the most appropriate and I will given to students at school. (Minute 0)

*(4) In every school are there general rules and more specific rules and general rules. (Minute 29)

*(5) when was they on detention is we will give treatment. (Minute 10)

The correction for number *(1) is the next chairman should modify the noun candidate. That is why the noun candidate comes first. As a result, there is $50 \%$ of the next chairman candidate of Indonesia..."

Then, in an information question, the helping verb must come after a question word then followed by subject and infinitive verb. Since the subject (suspect) is singular, therefore the suitable helping verb is does. It becomes "What does the suspect do in corruption?"

Next is number *(3). Since what are the most appropriate is a noun clause, the verb are should be placed after the noun phrase the most appropriate. Therefore, it becomes "...the discriminant of values genesis that form of punishment such as what the most appropriate are and I will give to students at school."Moving on to number *(4). To say that something exists in the particular place, there+be take place. Therefore are there should be inverted and become there are. The sentence should be In every school there are general rules and more specific rules and general rules.

The last, since when was they on detention is a noun clause, it should be a question word followed by subject and verb. Yet, pronoun they must be with be were. The correct one is when they were on detention is we will give treatment.

\section{The Causes of Errors}

\section{Samples' Personal Reasons}

Debaters had diversed reasons why they committed errors in stating arguments. When they were interviewed, they said that they were nervous and they were rushed by the time limit so they did not think about the grammar. In addition, they did not study deeply about the grammar so they just spit it out. Mostly, their major reasons why they committed errors was they had not got the knowledge about grammar learning. Thus, they did not read the text so it was kind of spontaneous.

\section{Personal Judgement}

\section{a. Native Language Interference}

Unlike English grammar, Bahasa Indonesia does not require any additional marker in a plural or countable noun or a singular verb. For example:

Incorrect sentence: "nowadays so many case about someone who punch into..."

Correct sentence: "nowadays so many cases about someone who punch into..."

Bahasa Indonesia only requires the repetition of the noun to state that the noun is more than one such as buku-buku and teman-teman. That is why, students tend to omit the plural noun marker when speaking.

Other example is the omission of singular verb marker s/es. In Bahasa Indonesia, when a third person singular speaks, there is no additional in the verb. For instance dia bermain bola setiap sore. While in English, the verb should be added with s/es. 


\section{b. Intralingual and Developmental Factors}

An error occurs because there is the similarity in the target language and a learner has not got more or deeper knowledge about grammar. This also happened to the debaters. Errors caused by the intralingual and developmental factors happened more frequently rather than errors caused by native language interference.

For example the wrong preposition for a phrasal verb. Students lack of knowledge about phrasal verbs.

Incorrect sentence:

"... from positive team totally agree about this motion if this house..."

Correct Sentence

"... from positive team totally agree with this motion if this house..."

The verb agree is always followed by the preposition with. Then, the preposition about should be replaced with the preposition with. This happened because students think that agree is always accompanied with about.

Incorrect sentence: "... will talk about the advantages of sport and politics are mix."

Correct sentence:

"...will talk about the advantages of

sport and politics are mixed.

\section{INTERPRETATION}

From the data analysis, the writer could infer that the major error that the students or the debaters made was misformation out of the other three types of error according with surface strategy taxonomy. It can be seen from each debater's argument that contained more than a half of misformation errors out of its total. For example, the use of gerund after preposition for. In this case, students used infinitive verb (without object) rather than gerund as in for make the soccer be better. Then, the misuse of infinitive verb for past participle in passive voice as in it should be repaire, and the mischoose of pronoun for singular or plural subject as in the example the politicians who join the sport is also 'cause its only have secret intention.

Therefore followed by omission where students usually did not attach singular verb marker s/es and plural noun marker as well which caused by the interference of native language. It was in line with what Touchie said as one of the sources of error. For instance the great conflict that cause the decreasing of achievement in PSSI and I have five reason.

While for addition, there was the existence of a pronoun after a subject as in FIFA its talk about the world regulation for football and soccer. The last, the misplace of adjective that modifies a noun in there are 50\% of candidate the next chairman of Indonesia and the misordering of information question where helping verb followed after the subject as in what the suspect do in corruption?.

The errors happened mostly because of the intralingual and developmental factors which is in accordance with what Keshavarz said because students find similarities in the target language and have not got or learned deeper knowledge about grammar learning such as using gerund, causative verbs, passive voice, so on. While errors because of the interference in native language happened lesser than the errors caused by intralingual and developmental factors. 
Talking about personal reasons why the errors happened, students made errors because they were nervous and rushed by the time limit when stating arguments. This caused them to have spoken quickly. Those made them forgot the grammar and just stated their arguments spontaneously without touching the grammar. Yet, speaking English with proper grammar especially when debating would give a clearer explanation and an aestetic in using the language. Unfortunately, learners especially students tend to avoid using proper grammar when speaking.

\section{CONCLUSION \& SUGGESTION}

\section{Conclusion}

Regarding to the finding and interpretation, the writer concluded that every debater in two debate sessions made grammatical errors in their arguments. Misformation is the major error that they made. The errors that they made were because of the interference of native language, intralingual and developmental factors or not getting sufficient knowledge about grammar, nervousness, and time limit. Those were the reasons that made them to speak without thinking about the grammar.

In fact, speaking English with correct grammar especially when debating would be easily received by the other speakers and the adjudicators and it would be more structured in producing statements. Those statements would give a clear clarification about the motion. Therefore, grammar would help the process of delivering arguments in a debate.

\section{Suggestions}

The writer would like to give some suggestions for the better grammar use and learning. The suggestions were divided into two groups which are for teachers and students. They were as follow:

\section{For Teachers}

a. Teachers should give intensive grammar learning so their students are not only brave in speaking English but also applying good grammar as well.

b. Teachers should train their students to speak English with grammar, not speaking English but leaving out the grammar. In this case, the more they practice, the more good production of words they have.

\section{For Students}

a. Students need to comprehend the grammar rules well. Then, they will find it challenging.

b. Students should apply proper grammar step by step even though there are so many rules in grammar.

c. Students should master the grammar, by way of going straight to applying the grammar in delivering arguments in debate which basically the debate has time limit and triggers the students to think critically and spontaneously.

d. Students should try to always comprehend the grammar and eventually they will get used to speaking English with good grammar not only in daily conversation or in debate competition even in larger events such as presenting something or delivering a paper.

3. For Debate Coach or Trainer 
a. Coach should also teach their debaters to apply grammar in delivering arguments for the sake of the clarity or the clearness of the point in arguments. In this case, the grammar learning that has been taught by the teacher can be directly applied either in internal debate or in larger scope.

b. Coach needs to train their debaters to always be relax even though they are nervous or have limited time so the debaters can deliver their arguments well without leaving out the grammar. This can be the great point in winning a debate competition.

\section{ACKNOWLEDGMENTS}

Thank you so much to the experts for developing the template so I can work on my journal with ease.

\section{REFERENCES}

1. Besnar, P. \& Hunter, A. (2008). Elements of Argumentation. England: The MIT Press.

2. Broughton, G. \& Brumfit, C. \& Pincas, A. \& Wilde, R.D. (1980). Teaching English as a Foreign Language. New York, NY : Routlegde.

3. Cohen, L. \& Manion, L. \& Morison, K. (2007). Research Methods in Education (6 ${ }^{\text {Th }}$ ed.). Canada, CN: Routledge.

4. Creswell, J. W. (2014). Research Design : Qualitative, Quantitative, and Mixed Methods Approaches 4th Edition. USA: SAGE Publications.

5. Downing, A. \& Locke, P. (2006). English Grammar: A University Course Second Edition. Canada, CN: Routledge.

6. Dulay, H. \& Burt, M. \& Krashen, S. (1982). Language Two. New York, NY: Oxford University Press.

7. Richards, J. (1971). Error Analysis and Second Language Strategies. Canada, CN: Department of Linguistics University Laval.

8. Susanti, R. (2016). STUDENTS' PERCEPTIONS TOWARDS THE EFFECTIVE FEEDBACK PRACTICES IN THE LARGE EFL WRITING CLASS BASED ON STUDENTS' ENGLISH PROFICIENCY LEVEL. Journal of Advances in Linguistics.

9. Syahri, I. \& Susanti, R. (2016). An Analysis of Local and Target Culture Integration in the English Textbooks for Senior High School in Palembang. Journal of Education and Human Development.

10. Richards, J.C. \& Schmidt, R. (2010). Longman Dictionary Of Language Teaching And Applied Linguistics. ( $4^{\text {th }}$ ed.). London: Pearson Education

11. Syahri, I. \& Sulaiman, M. \& Susanti, R. (2017). Metodologi Penelitian Pendidikan Bahasa. Palembang, PLG: Universitas Muhammadiyah Palembang.

12. Touchie, H. Y. (1986). Second Language Learning Errors: Their Types, Causes, And Treatment. JALT Journal, 77.

13. Wingate, U. (2012). 'Argument!' helping students understand what essay writing is about. Journal of English for Academic Purposes, 2. 
Volume : 09 Issue : 01

Journal Of Advances In Linguistics

\section{Author' biography with Photo}

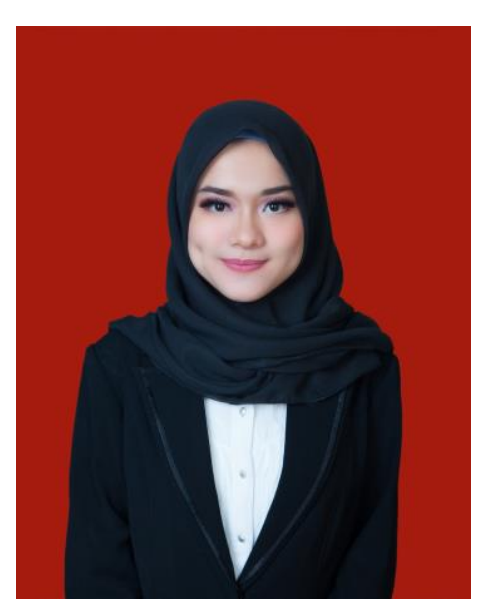

Adina Nikmawati was born in Palembang on November 1 st, 1995 . Adina graduated from Senior High School number 3 Palembang. She decided to be student of English study program since her passion is speaking English. In facilitating her passion, she joined English courses and reads English novels. She wants to be either a public relation or a lecturer of English.

During her study, she had teaching practice experience (PPL) in Senior High School number 1 Palembang. There the writer was taught to not only teach, but also be friends with the students. While to give a contribution to the university, she becomes the part of Ikatan Putera Puteri Universitas Muhammadiyah Palembang. In order to achieve bachelor degree, she conducted a study entitled Grammatical Errors in Debate Arguments Made by Students of Global English Language Center. 